\title{
The scientific research on ecosystem services: A bibliometric analysis
}

\section{Valentina H. Pauna, Flavio Picone, Gianpiero Le Guyader, Elvira Buonocore, Pier Paolo Franzese*}

\author{
Laboratory of Ecodynamics and Sustainable Development, Department of Science and Technology, \\ Parthenope University of Naples, Italy \\ e-mail: pierpaolo.franzese@uniparthenope.it
}

Received: 10 May 2018 / Accepted: 25 July 2018

\begin{abstract}
The scientific research on ecosystem services (ES) has grown substantially over the past ten years, making more evident the vital role played by natural ecosystems in support of human economy and well-being. Several studies showed that biodiversity represents a fundamental part of the Earth's life support system. Biodiversity considerably affects ecosystem functioning while contributing to the provision of different types of ES. The increasing ecological awareness of scientists, citizens, and policy makers on the importance of natural capital stocks and ES flows boosted nature conservation strategies and the development of more environmentally friendly production processes. In this study, we explored the global scientific literature on ES over the last thirty years. The software VOSviewer was used to create maps based on network data of scientific publications displaying relationships among scientific journals, researchers, and countries. Specific keywords were finally used to explore the co-occurrence of different terms connected to the research on ES. Results show that the Millennium Ecosystem Assessment had a major impact on the scientific literature dealing with the ES concept. The top country researching on ES was USA, while the top journal was Ecological Economics. In terms of co-occurrence, the top keywords were "biodiversity", "management", "conservation", and "climate change". This study identified the main research areas characterizing the scientific literature on ES. Social network analysis and maps based on network data make possible the application of systems thinking in bibliometric science. This type of analysis allows for the investigation of research development in specific fields of science, capturing the interdisciplinarity of research topics crossing the boundary of specific disciplines, as it is the case of ES.
\end{abstract}

Keywords: Ecosystem services, bibliometric analysis, VOSviewer, social network analysis.

\section{Introduction}

Human life and well-being are strongly dependent on nature and rely on the variety of services that ecosystems provide (Daily, 1997). The concept of ecosystem services (ES) was first introduced by Erlich and Erlich (1981) as a way to express how society values natural functions. In 1997, Daily defined ES as "the conditions and processes through which natural ecosystems, and the species that make them up, sustain and fulfill human life" (Daily, 1997). In the same year, Costanza et al. (1997) conducted a quantitative assessment of the value of the world's ES, which led to a considerable increase in the research and application of the concept at academic and institutional levels. Since then, the attention on the subject has grown exponentially, especially considering the ongoing depletion and degradation of natural systems caused by anthropogenic activities occurring worldwide (Costanza et al., 2017). Given the increased awareness on the importance of the ES concept, many international initiatives have been launched to standardize the definition, classification, and assessment of ES (Table 1).

In 2000, the United Nations launched the Millennium Ecosystem Assessment (MA), an international initiative to assess the consequences of ecosystem change on human well-being. The MA synthesized existing information from 
scientific literature and provided knowledge about the condition and trends of the world's ecosystems and their services. According to the MA, ES can be broadly classified in four categories: 1) provisioning services (i.e., the provision of products from ecosystems), 2) regulating services (i.e., benefits derived from the regulative action of ecosystem processes), 3) cultural services (i.e., non-material benefits derived from ecosystems), and 4) supporting services (i.e., ES that are necessary for the maintenance of all other ES). In 2005, the MA established that humans had already degraded $60 \%$ of the Earth's ecosystems, jeopardizing their ability to provide services and sustain future generations. Finally, the MA concluded that actions could be taken to restore most of the degraded ES, assuming substantial changes in policy and management practices (MA, 2005).

Following the MA, The Economics of Ecosystems and Biodiversity (TEEB) global initiative was launched by Germany and the European Union in 2007. The main goal was to make nature's value visible in decision-making at all levels, by recognizing the wide range of benefits provided by ecosystems and biodiversity and valuing them in economic terms (TEEB, 2010).

In 2011, the European Union adopted The Biodiversity Strategy 2020 with the aim to stop the loss of global biodiversity and ES. In particular, one of its targets focuses on maintaining and enhancing ES in the territory of the Member States by 2020 (Maes et al., 2013).

Another important contribution that highlights the increasing international relevance of the ES concept is represented by the Intergovernmental Platform on Biodiversity and Ecosystem Services (IPBES) established by the UN in 2012. Its mission was to create a science-policy interface by recommending tools and methods for sustainable development while encouraging the assessment of ES and related benefits for humans (Díaz et al., 2015).

Finally, released in 2013 and updated in 2016, the Common International Classification of Ecosystem Services (CICES) builds upon other existing classifications to favor a better understanding of how ES are measured and analyzed. Differently from other classifications, CICES makes a distinction between services and benefits, and does not include the supporting services category, considered to be underlying the ecosystems functioning (Haines-Young and Potschin, 2013; Potschin and Haines-Young, 2016).

Since its first formulation, the ES concept has been widely applied through ecological and socio-economic assessments. These assessments have supported decisionmaking processes, also increasing the understanding of the value of nature in support of human economy (Buonocore et al., 2018; Häyhä and Franzese, 2014).

Table 1. Main international initiatives regarding ES and their relative objectives

\begin{tabular}{|c|c|c|}
\hline Name & Year & Objective \\
\hline $\begin{array}{l}\text { Millennium Ecosystem } \\
\text { Assessment (MA) }\end{array}$ & 2005 & $\begin{array}{l}\text { Understanding the state of ES, trends in production and flow of ES, } \\
\text { and major pressures and threats for ES to improve management } \\
\text { decisions and policy formulations (www.millenniumassessment.org) }\end{array}$ \\
\hline $\begin{array}{l}\text { The Economics of Ecosystems } \\
\text { and Biodiversity (TEEB) }\end{array}$ & 2007 & $\begin{array}{l}\text { Making nature visible in economic decisions by mainstreaming } \\
\text { the values of biodiversity and ecosystem services into decision making } \\
\text { at all levels (www.teebweb.org) }\end{array}$ \\
\hline $\begin{array}{c}\text { The Intergovernmental Platform } \\
\text { on Biodiversity and Ecosystem } \\
\text { Services (IPBES) }\end{array}$ & 2012 & $\begin{array}{l}\text { Strengthening the science-policy interface for biodiversity and } \\
\text { ecosystem services for the conservation and sustainable use of } \\
\text { biodiversity, long-term human well-being and sustainable development } \\
\text { (www.ipbes.net) }\end{array}$ \\
\hline $\begin{array}{l}\text { Common International } \\
\text { Classification of Ecosystem } \\
\text { Services (CICES) }\end{array}$ & $\begin{array}{c}2013 \\
\text { Updated in } 2016\end{array}$ & Classifying the outputs of ecosystem services (www.cices.eu) \\
\hline
\end{tabular}


The goal of the present study is to explore the global scientific literature on ES to track the evolution and trends on the topic over the last three decades. A bibliometric analysis was conducted to create maps based on network data of scientific publications displaying relationships among scientific journals, researchers, and countries. Specific keywords were finally used to explore the co-occurrence of different terms connected to the research on ES. This approach allowed for the identification of the main areas and actors linked to the research on ES.

\section{Methodology}

\subsection{Bibliometric analysis}

The review of the scientific literature on ES was conducted through a bibliometric analysis. Bibliometrics uses statistics and quantitative analysis to investigate knowledge structure and development of research fields (Reuters, 2008; Zou et al., 2018). Such analysis allows for the construction of a network based on the relationships between countries, journals, organizations, authors and keywords dealing with the investigated topic (Chen et al., 2016).
In this study, the bibliometric analysis was performed using the software VOSviewer (version 1.6.8). VOSviewer is a software tool based on social network analysis allowing for the creation, visualization, and exploration of maps based on bibliometric network data, displaying clusters that support the classification of output results. The main technical terms used by the software are explained in Table 2.

VOSviewer can generate different types of bibliometric networks and maps. In this study, we performed coauthorship, co-occurrence, and citation analyses to create maps showing the network of: (1) the co-authorship among researchers and countries, (2) cited scientific journals, and (3) the co-occurrence of keywords (Table 3). In each of these maps, the size of items is determined by their "total link strength" while the thickness of each connection is based on the "link strength" (Table 2).

The number of clusters is determined by the resolution parameter. The higher its value, the higher the level of detail and consequently the number of clusters. Its value can be arbitrarily set by the user to visualize an appropriate number of clusters in the maps (Van Eck and Waltman, 2018). In our case, we applied a resolution equal to 1 for all the analyses.

Table 2. Terminology used by VOSviewer software (Van Eck and Waltman, 2018)

\begin{tabular}{|c|c|}
\hline Term & Description \\
\hline Items & Objects of interest (e.g., publications, researchers, keywords, authors). \\
\hline Link & Connection or relation between two items (e.g., co-occurrence of keywords). \\
\hline Link strength & $\begin{array}{l}\text { Attribute of each link, expressed by a positive numerical value. In the case of co-authorship links, } \\
\text { the higher the value, the higher the number of publications the two researchers have co-authored. }\end{array}$ \\
\hline Network & Set of items connected by their links. \\
\hline Cluster & Sets of items included in a map. One item can belong only to one cluster. \\
\hline $\begin{array}{l}\text { Weight attribute: } \\
\text { number of links }\end{array}$ & The number of links of an item with other items. \\
\hline $\begin{array}{l}\text { Weight attribute: } \\
\text { total link strength }\end{array}$ & The cumulative strength of the links of an item with other items. \\
\hline
\end{tabular}

Table 3. Different VOSviewer types of analyses used in this study (Van Eck and Waltman, 2014, 2018)

\begin{tabular}{|c|c|}
\hline Types of analysis & Description \\
\hline Co-authorship & $\begin{array}{l}\text { In co-authorship networks, researchers, research institutions, or countries are linked to each other } \\
\text { based on the number of publications they have authored jointly. }\end{array}$ \\
\hline Co-occurrence & $\begin{array}{l}\text { The number of co-occurrences of two keywords is the number of publications in which both } \\
\text { keywords occur together in the title, abstract or keyword list. }\end{array}$ \\
\hline Citation & In citation networks, two items are linked if at least one cites the other. \\
\hline
\end{tabular}




\subsection{Bibliographic research and data collection}

Documents were collected on July $13^{\text {th }}, 2018$ by research on the web search engine Web of Science. The search string used was composed by the term "ecosystem services". The research was performed using a time frame from 1990 to 2018 and the Web of Science Core Collection database. The data were saved as "Tab-delimited (Win)" files from "Full Record" and "Full Record and Cited References" record contents. The "Full Record" content was used for co-authorship analyses (i.e., authors and countries network maps) and for the analysis of the co-occurrence of keywords. Finally, the "Full record and Cited References" data were used for the citation analysis of scientific journals.

Given the impact that MA had on the diffusion and development of the ES concept in various scientific domains, two sets of analyses were performed in the case of co-occurrence of keywords, namely before and after the release of the final MA report (2005). Therefore, in this last case the timespans used were from 1990 to 2005 (before MA, referred to as "BMA") and from 2006 to 2018 (after MA, referred to as "AMA").

\subsection{Temporal trend analysis}

In addition to the bibliometric network analysis, we performed an analysis of the temporal trend of the number of publications for each year. The trend was investigated before and after the MA final report (i.e., 1990 - 2005 and 2006 - 2017, respectively). Being still in progress, the year 2018 was omitted from this analysis.

\section{Results and discussion}

\subsection{Temporal trend analysis}

Overall, the search on the Web of Science Core Collection database produced 24,400 scientific articles published from 1990 to 2017 . The search resulted in 1,485 and 22,915 articles for the BMA and the AMA timespans, respectively. Figure 1 shows the trends associated with the two timespans. Differently from the BMA timespan, whose increase is expressed by a linear function $\left(\mathrm{R}^{2}=0.94\right)$, the AMA trend shows instead an exponential growth $\left(\mathrm{R}^{2}=0.99\right)$. This outcome highlights the major impact on the scientific

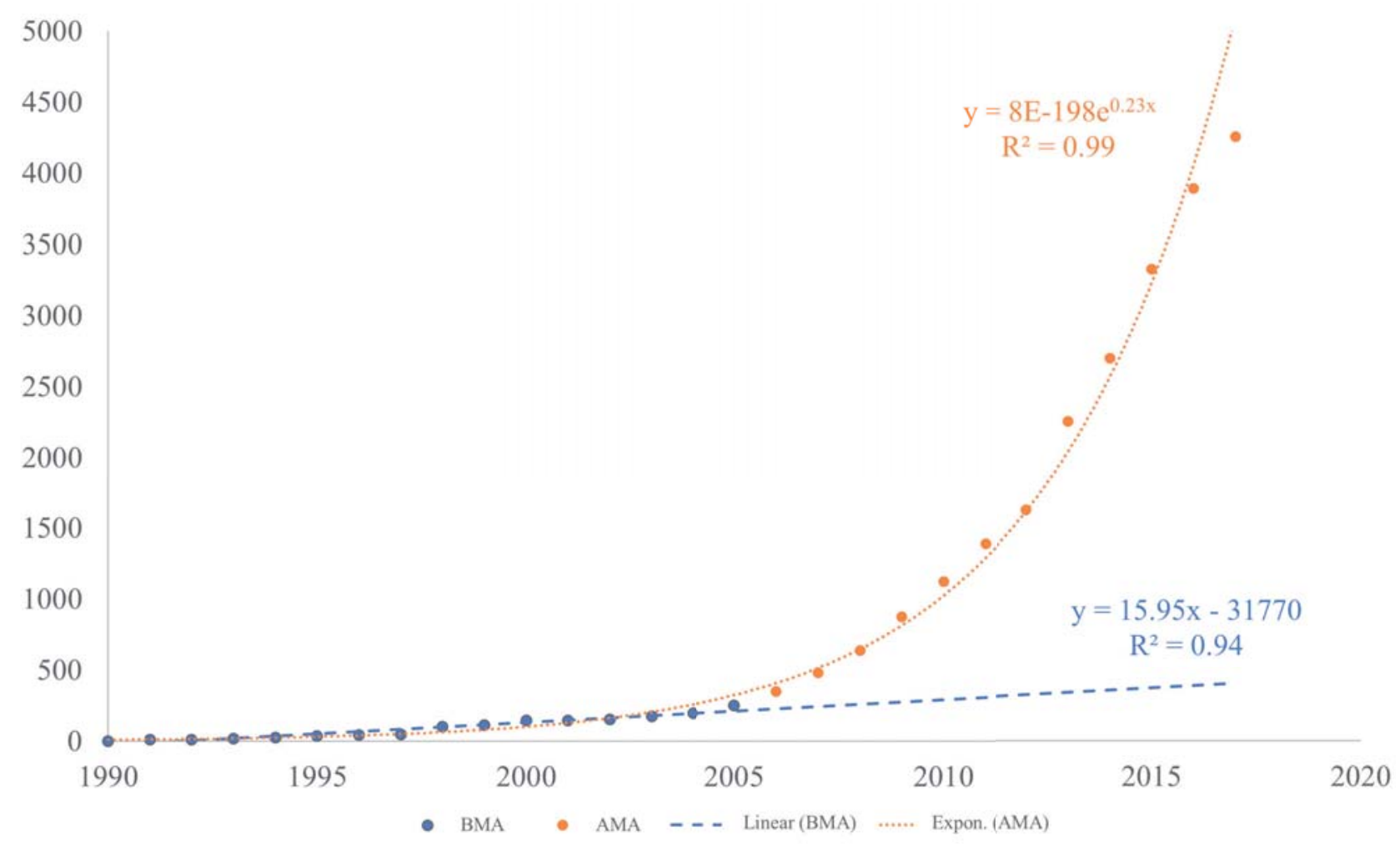

Figure 1. Temporal trends of scientific articles published before MA (BMA, blue line) and after MA (AMA, orange line) 
community generated by the MA which boosted the application of the ES concept in different fields of science.

\subsection{Bibliometric network analysis}

The bibliometric network analysis generated five different network maps (Fig. 2-6). For each map, we report the five most important items based on total link strength (Table 4-8).

\subsubsection{Co-authorship authors network}

The co-authorship analysis of authors resulted in 63,325 authors. By default settings of VOSviewer, we omitted articles with a number of co-authors greater than 25 to avoid considering negligible contributions in the network map. Applying a threshold of a minimum of 5 articles published per author, 3,863 authors were selected. The analysis resulted in 13 clusters (Fig. 2). The top five authors based on total link strength are reported in Table 4.

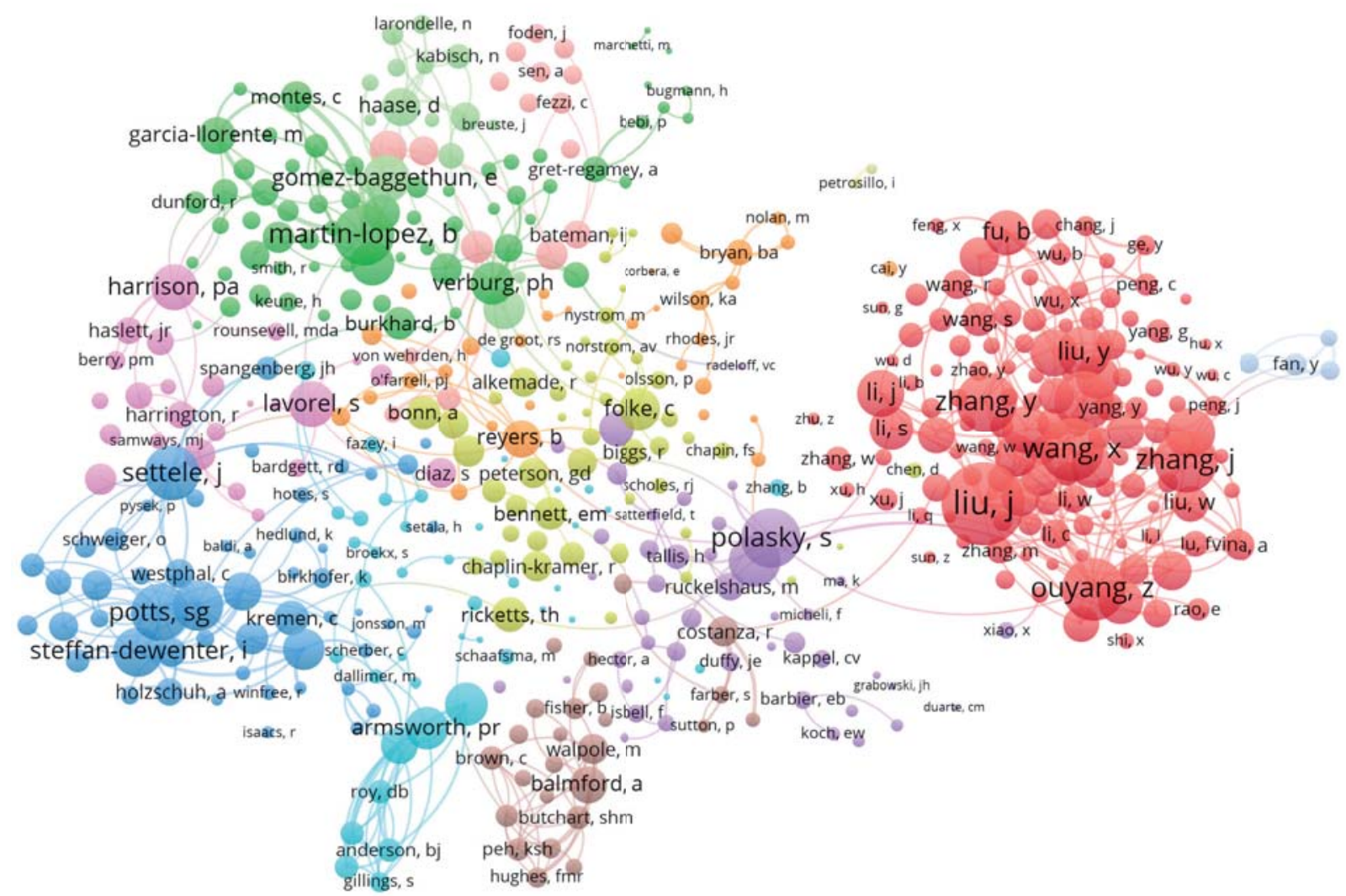

Figure 2. Co-authorship network map of authors publishing on ES from 1990 to 2018

Table 4. Top 5 authors publishing on ES (rank based on total link strength)

\begin{tabular}{|c|c|c|c|c|}
\hline Author & Total link strength & Links & Articles & Citations \\
\hline Liu, J. & 312 & 105 & 125 & 2,560 \\
\hline Wang, X. & 222 & 88 & 84 & 815 \\
\hline Ouyang, Z. & 218 & 63 & 41 & 8,486 \\
\hline Zhang, J. & 215 & 93 & 103 & 859 \\
\hline Zhang, Y. & 207 & 89 & 1,372 \\
\hline
\end{tabular}


The analysis produced several well-defined clusters of authors publishing on ES. Many relevant authors on the subject are placed in the center of their respective clusters, highlighting the importance of their contributions to the development of the research on ES.

It is worth noting that all the top five authors are Chinese and belong to the same cluster, suggesting a considerable research effort of the Chinese scientific community on the ES topic, even though their cluster is not showing many interconnections with the other clusters.

\subsubsection{Co-authorship countries network}

The co-authorship analysis of countries provided 194 results. Articles co-authored by researchers belonging to more than 25 countries were not included in the analysis. Applying a threshold of a minimum of 5 documents published per country, 136 countries were selected. The analysis generated 6 different clusters (Fig. 3). The first five countries based on total link strength are shown in Table 5.

USA ranks higher than all the other countries in all the parameters: total link strength, links, articles, and cita-

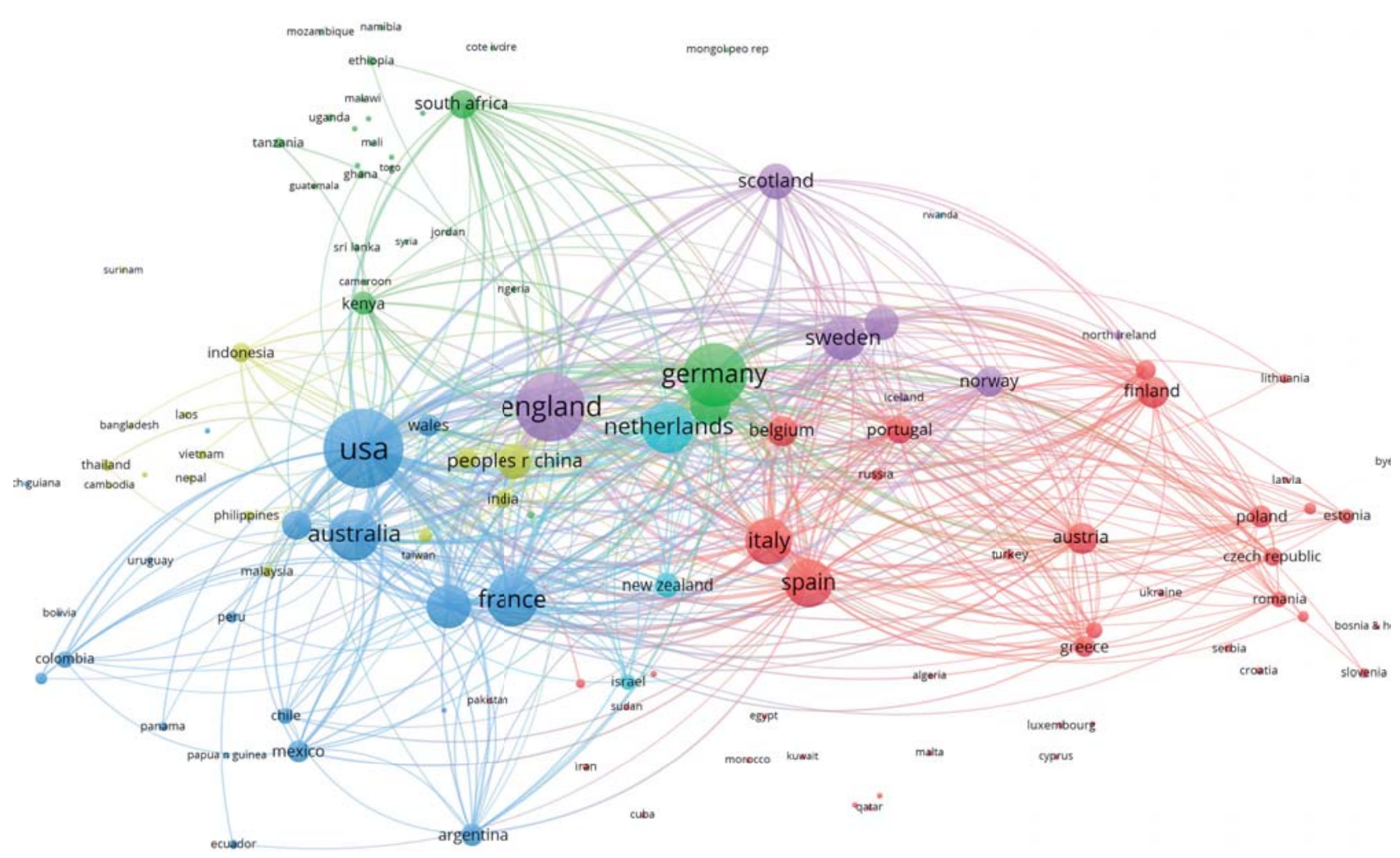

Figure 3. Co-authorship network map of countries publishing on ES from 1990 to 2018

Table 5. Top 5 countries publishing on the ES topic (rank based on total link strength)

\begin{tabular}{|c|c|c|c|c|}
\hline Country & Total link strength & Links & Articles & Citations \\
\hline USA & 8,758 & 132 & 9,358 & 300,589 \\
\hline England & 6,899 & 122 & 3,263 & 119,742 \\
\hline Germany & 6,021 & 116 & 2,806 & 73,407 \\
\hline France & 4,447 & 119 & 1,811 & 48,079 \\
\hline Netherlands & 4,154 & 114 & 1,468 & 58,170 \\
\hline
\end{tabular}


tions. In particular, articles and citations are approximately three times bigger than those of England. Instead, the total link strength is comparable to the other countries, having a similar number of links.

It is interesting to note that, despite the major contribution of Chinese authors suggested by Fig. 2, People's Republic of China does not rank high in the co-author network map of countries (Fig. 3). This could be explained by intense intra-national research activity on the subject, not followed by high collaborations with other countries.

\subsubsection{Citation analysis of journals}

By setting a threshold of at least 5 articles per journal, the citation analysis of journals generated 693 out of a total of 4,141 journals. The results of the analysis show 14 different clusters (Fig. 4). Table 6 reports the first five journals based on total link strength.

The results of the citation analysis of journals reflect relevant research domains dealing with ES. The journals Ecological Economics and Ecosystem Services rank higher

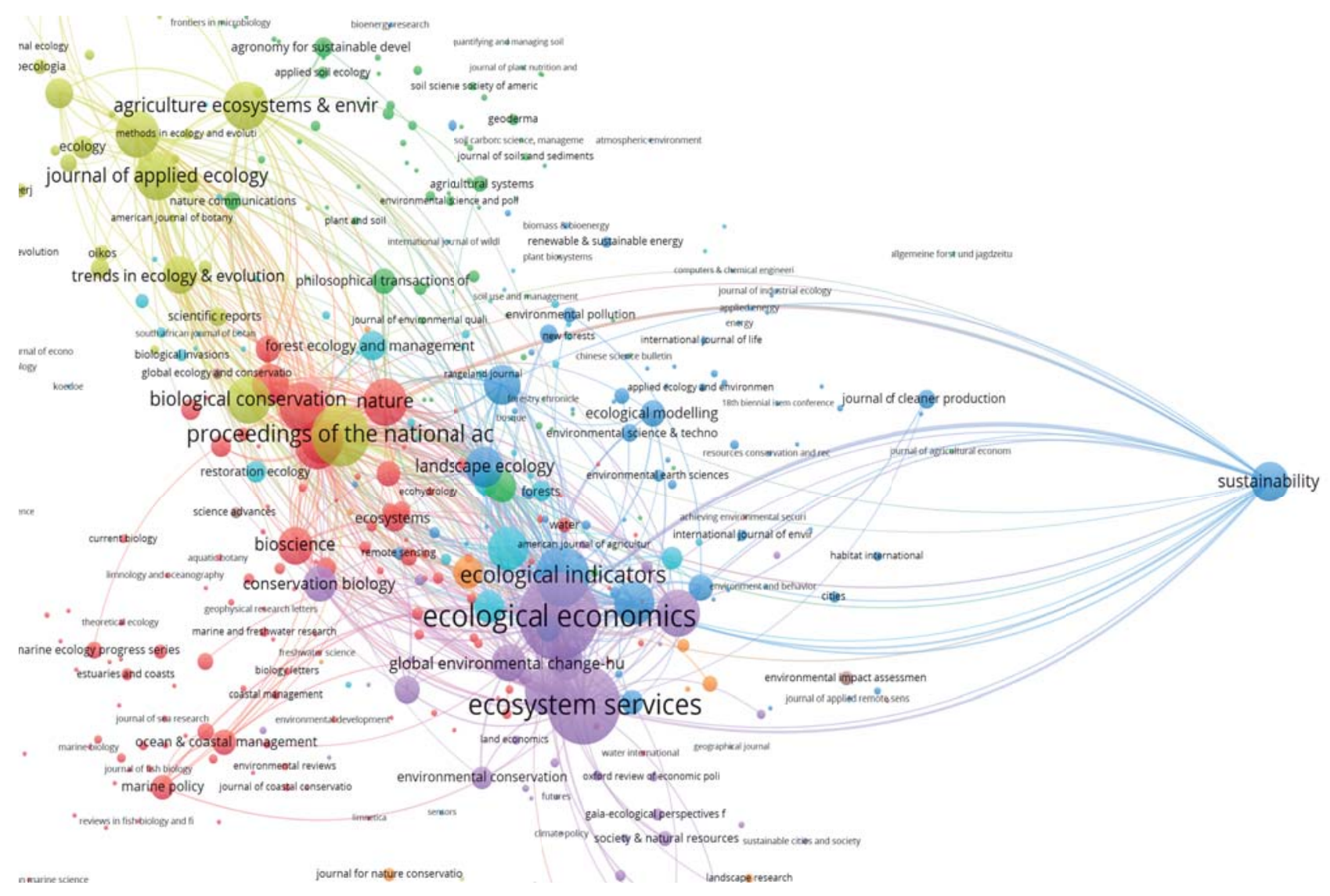

Figure 4. Citation network map of journals publishing on the ES topic from 1990 to 2018

Table 6. Top 5 journals publishing on the ES topic (rank based on total link strength)

\begin{tabular}{|c|c|c|c|c|}
\hline Journal & Total link strength & Links & Articles & Citations \\
\hline Ecological Economics & 19,226 & 463 & 636 & 29,697 \\
\hline Ecosystem Services & 15,717 & 408 & 723 & 26,740 \\
\hline $\begin{array}{c}\text { Proceedings of the National } \\
\text { Academy of Sciences of the } \\
\text { USA }\end{array}$ & 9,644 & 429 & 247 & 8,208 \\
\hline Ecological Indicators & 9,211 & 370 & 460 & 8,610 \\
\hline Plos One & 6,093 & 376 & 543 & \\
\hline
\end{tabular}


than all other journals, showing the relevance of ecological and socio-economic studies in relation to ES research.

It is noteworthy that the journal Ecosystem Services is ranked as the second most important, despite its recent foundation in 2012. This is likely due to its main focus on ES research in addition to the increasing attention given to the ES topic by the scientific community.

\subsubsection{Co-occurrence of keywords}

The co-occurrence analysis of keywords was performed for the periods BMA (1990-2005) and AMA (2006-2018). For both analyses, a threshold of a minimum number of keyword occurrences equal to 5 was set. The BMA analysis resulted in 324 keywords out of a total of 5,535. Results show 7 different clusters (Fig. 5). Table 7 reports the first five keywords based on total link strength.

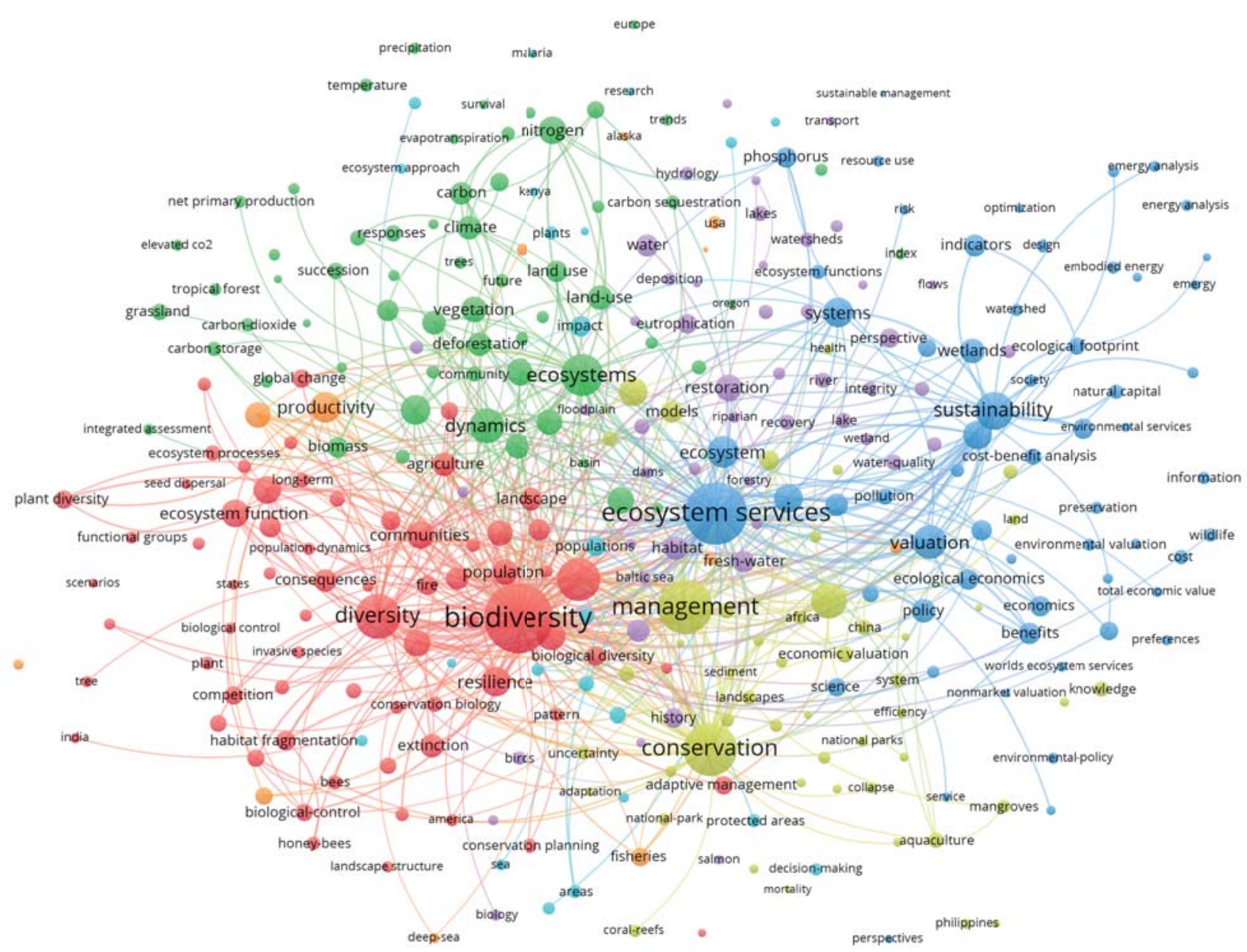

Figure 5. Co-occurrence network map of keywords from articles published on ES before the publication of the MA report (1990-2005)

Table 7. Top 5 keywords co-occurring in articles published on ES before the publication of the MA report (rank based on total link strength)

\begin{tabular}{|c|c|c|c|}
\hline Keyword & Total link strength & Links & Occurrences \\
\hline Biodiversity & 996 & 250 & 187 \\
\hline Ecosystem Services & 794 & 245 & 194 \\
\hline Management & 607 & 213 & 114 \\
\hline Conservation & 568 & 201 & 75 \\
\hline Diversity & 423 & 158 & \\
\hline
\end{tabular}


Although the keyword "ecosystem services" had the most occurrences (194), "biodiversity" ranked higher in terms of total link strength (996) than "ecosystem services" (794). This outcome is due to the stronger links of "biodiversity" compared to "ecosystem services". This could be explained by the fact that, before the publication of the MA, "biodiversity" was already a well-established concept and therefore more strongly connected to other research topics dealing with ES. Furthermore, the results highlight how the ES concept was already investigated for management and conservation purposes (Fig. 5).

The AMA analysis generated 7,521 out of 66,193 keywords, showing 5 different clusters (Fig. 6). Table 8 shows the first five keywords based on total link strength.

Apart from "climate change", the AMA analysis showed the same top keywords as the BMA analysis.

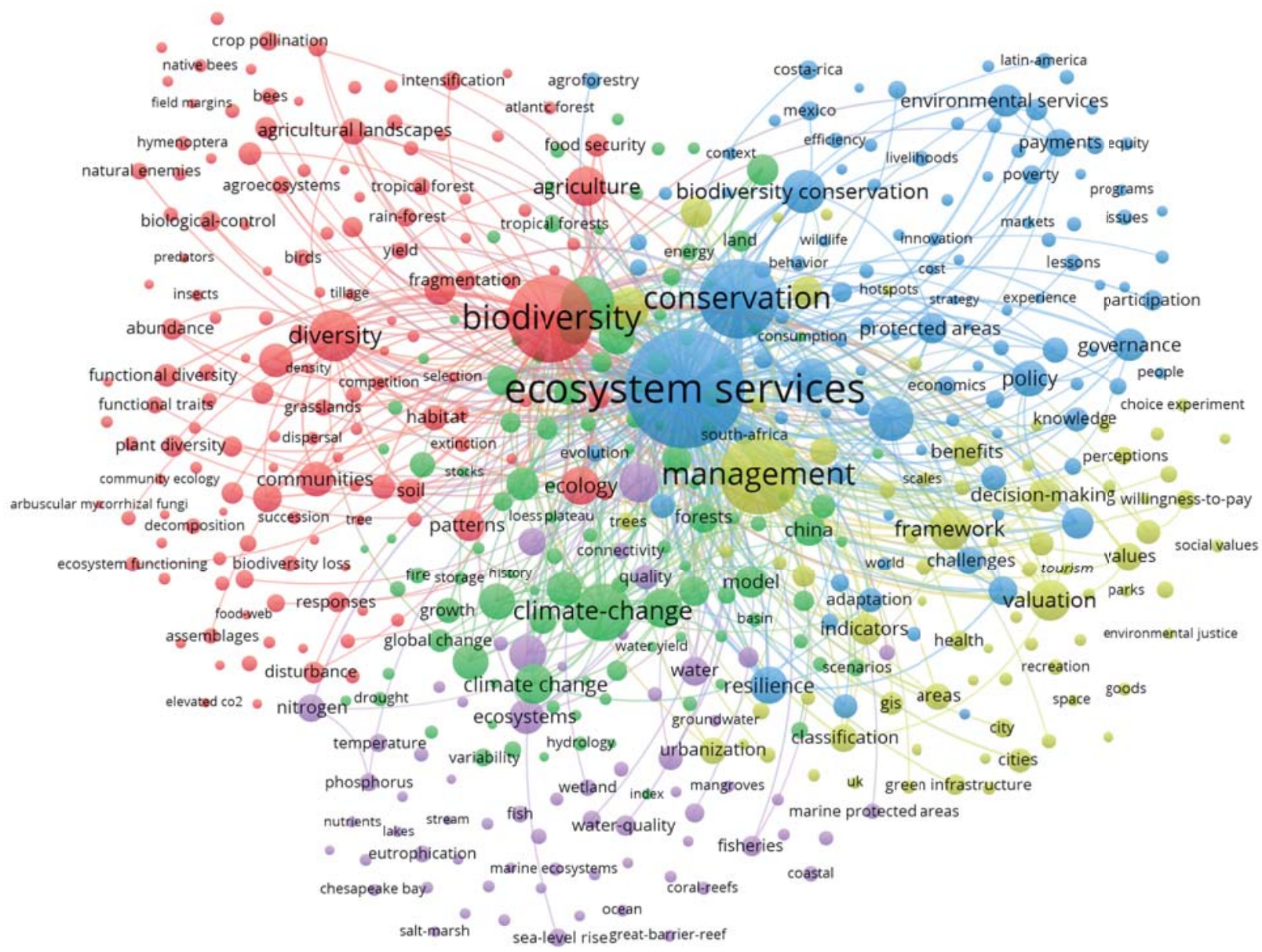

Figure 6. Co-occurrence network map of keywords from articles published on ES after the publication of the MA report (2006-2018)

Table 8. Top 5 keywords co-occurring in articles published on ES after the publication of the MA report (rank based on total link strength)

\begin{tabular}{|c|c|c|c|}
\hline Keyword & Total Link Strength & Links & Occurrences \\
\hline Ecosystem Services & 55,153 & 599 & 9,490 \\
\hline Biodiversity & 30,283 & 599 & 4,422 \\
\hline Conservation & 24,257 & 596 & 3,524 \\
\hline Management & 24,208 & 597 & 3,749 \\
\hline Climate Change & 13,261 & 595 & 2,206 \\
\hline
\end{tabular}


Although "ecosystem services" shows more than double the occurrences than "biodiversity" (9,490 vs. 4,422) and a much higher total link strength $(55,153)$, it has almost the same number of links as the other top keywords. The total link strength shows that the concept of ES gained more attention in the scientific literature. In addition, results also suggest that climate change has become closely related to the study of ES in recent years.

\section{Conclusions}

In this study, we explored the global scientific literature on ecosystem services over the last thirty years. The attention drawn by the concept of ES has exponentially increased over time, especially after the publication of the MA report in 2005. The bibliometric analysis performed by using VOSviewer not only showed an increasing number of articles published on ES, but also allowed for investigating the relationships occurring among authors, journals, and countries dealing with the ES topic.

Social network analysis and maps based on network data make possible the application of systems thinking in bibliometric science and the analysis and visualization of a large amount of data. This type of analysis allows for the investigation of research development in specific fields of science, generating quantitative statements that capture the interdisciplinarity of research topics crossing the boundary of specific disciplines, as it is the case of ES.

\section{References}

Buonocore, E., Picone, F., Russo, G.F., Franzese, P.P. , 2018, The Scientific Research On Natural Capital: A Bibliometric Network Analysis. Journal of Environmental Accounting and Management, 6(4), 374-384.

Chen D., Liu Z., Luo Z., Webber M., Chen J., 2016, Bibliometric and visualized analysis of emergy research, Ecological Engineering 90: 285-293.

Costanza R., D’Arge R., de Groot R., Farber S., Grasso M., Hannon B., van den Belt M., 1997, The value of the world's ecosystem services and natural capital, Nature 387 (6630): 253-260.

Costanza R., de Groot R., Braat L., Kubiszewski I., Fioramonti L., Sutton P., Grasso M., 2017, Twenty years of ecosystem services: How far have we come and how far do we still need to go?, Ecosystem Services 28: $1-16$.

Daily G.C., 1997, Nature's Services: Societal Dependence on Natural Ecosystems, Island Press, Washington DC.

Díaz S., Demissew S., Carabias J., Joly C., Lonsdale M., Ash N., Zlatanova D., 2015, The IPBES Conceptual Framework - connecting nature and people, Current Opinion in Environmental Sustainability 14: 1-16.

Ehrlich P.R., Ehrlich A.H., 1981, Extinction: the causes and consequences of the disappearance of species, Random House, New York.

Haines-Young R., Potschin M., 2013, Common International Classification of Ecosystem Services (CICES), Version 4.3. Report to the European Environment Agency EEA/BSS/07/007.

Häyhä T., Franzese P.P., 2014, Ecosystem services assessment: A review under an ecological-economic and systems perspective, Ecological Modelling 289: 124-132.

MA, 2005, Ecosystems and Human Well-Being: Multiscale Assessments. Findings of the Sub-Global Assessments Working Groups, Island Press, Washington DC.

Maes J., Teller A., Erhard M., Liquete C., Braat L., Berry P., et al., 2013, Mapping and Assessment of Ecosystems and their Services. An analytical framework for ecosystem assessments under action 5 of the EU biodiversity strategy to 2020, Publications office of the European Union, Luxembourg.

Potschin M., Haines-Young R., 2016, Defining and measuring ecosystem services, [in:] Routledge Handbook of Ecosystem Services, M. Potschin, R. Haines-Young, R. Fish, R.K. Turner (eds), Routledge, London and New York: 25-44.

Reuters T., 2008, Whitepaper Using Bibliometrics, Thomson Reuters, $12 \mathrm{pp}$.

TEEB, 2010, The Economics of Ecosystems and Biodiversity: Mainstreaming the Economics of Nature: A Synthesis of the Approach, Conclusions and Recommendations of TEEB.

Van Eck N.J., Waltman L., 2014, Visualizing bibliometric networks, [in:] Measuring scholarly impact: Methods and practice, Y. Ding, R. Rousseau, D. Wolfram (eds): 285-32, Springer.

Van Eck N.J., Waltman L., 2018, Manual for VOSviewer version 1.6.8, CWTS Meaningful Metrics, Universiteit Leiden.

Zou X., Long W., Le H., 2018, Visualization and analysis of mapping knowledge domain of road safety studies. Accident Analysis \& Prevention 118: 131-145. 